\title{
Observer Based Robust Position Control of a Hydraulic Servo System Using Variable Structure Control
}

\author{
E. Kolsi-Gdoura, M. Feki, and N. Derbel \\ Research Group CEMLab, National Engineering School of Sfax, University of Sfax, 1073 Sfax, Tunisia \\ Correspondence should be addressed to M. Feki; moez.feki@enig.rnu.tn
}

Received 8 May 2015; Revised 9 July 2015; Accepted 12 July 2015

Academic Editor: Rongwei Guo

Copyright ( 2015 E. Kolsi-Gdoura et al. This is an open access article distributed under the Creative Commons Attribution License, which permits unrestricted use, distribution, and reproduction in any medium, provided the original work is properly cited.

\begin{abstract}
This paper deals with the position control of a hydraulic servo system rod. Our approach considers the surface design as a case of virtual controller design using the backstepping method. We first prove that a linear surface does not yield to a robust controller with respect to the unmatched uncertainty and perturbation. Next, to remedy this deficiency, a sliding controller based on the secondorder sliding mode is proposed which outperforms the first controller in terms of chattering attenuation and robustness with respect to parameter uncertainty only. Next, based on backstepping a nested variable structure design method is proposed which ensures the robustness with respect to both unmatched uncertainty and perturbation. Finally, a robust sliding mode observer is appended to the closed loop control system to achieve output feedback control. The stability and convergence to reference position with zero steady state error are proven when the controller is constructed using the estimated states. To illustrate the efficiency of the proposed methods, numerical simulation results are shown.
\end{abstract}

\section{Introduction}

Actually, the hydraulic servo systems are very popular in several industrial applications such as robotics, aerospace flight-control actuators, heavy machinery, aircrafts, automotive industry, and a variety of automated manufacturing systems. This is mainly due to their ability to produce high power and accurate and fast responses. However, these systems have a high nonlinear behavior due to the pressure flow characteristics [1] and the leakage model inside the servovalves [2]. This fact makes the control design for precise output tracking a very challenging task.

Owing to their simplicity, linear controllers of PID type $[3,4]$, input/output linearization controllers [5-9], and also sliding mode controllers (SMC) [10-13] have been used to control the hydraulic servo systems. However, such controllers were designed based on the plant physical model and, therefore, the plant parameters knowledge is required. Consequently, they were shown to be highly sensitive to mismatched perturbation and uncertainties, thus resulting in performance degradation.

To improve the controller performances, several strategies have been adopted such as using the self-tuned PID controller [14, 15] and nonlinear adaptive controllers [1618]. SMC appended with some improvements have also been used. In $[19,20]$ SMC method has been combined with an adaptive controller, which can compensate for the system uncertain nonlinearities, for linear uncertain parameters, and especially for the nonlinear uncertain parameters to construct an asymptotically stable tracking. In [21], SMC has been used with the PID controller to achieve control of asymmetrical hydraulic cylinder trajectory tracking. To drive electrohydraulic actuators, various robust control techniques, such as $\mathscr{H}_{2}$ and $\mathscr{H}_{\infty}$ controls, were applied [22-24]. This approach enabled the compensation for the inherent nonlinearities of the actuator and rejects matched external disturbances and attenuates mismatched external disturbances. To cope with mismatched disturbances authors used the integral SMC and to remedy the slow response due to windup phenomenon a realizable reference compensation has been used to achieve fast position tracking $[25,26]$. Since it has been proposed by Levant $[27,28]$, higher-order SMC (HOSMC) has been widely used to control electrical drives $[29,30]$, electropneumatic actuators [31], and electrohydraulic actuators [32,33]. 
In the present paper, we are interested in controlling the position of the rod in a hydraulic servo system that consists of a four-way spool valve supplying a double effect linear cylinder with a double-rodded piston. The piston is driving a load modeled by a mass, a spring, and a sliding viscous friction. Our work aims to design a controller that may achieve the reference position in presence of mismatched parameter uncertainty and perturbation in addition to actuator saturation. To realize this objective, we start in the second section by formulating the problem and presenting the effects of using first- and second-order SMC with a linear surface. In Section 3, we present the design of a sliding surface obtained using backstepping method and variable structure controller, leading hence to a nonlinear surface that allows achieving the reference output despite the presence of uncertainties and perturbations. Numerical simulation results are presented to illustrate the efficiency of the proposed control design. In Section 4, we present a sliding observer and prove the convergence of the observer as well as the exact position tracking using the nonlinear surface SMC issued from the observer states. Finally, the conclusion and some remarks are presented in Section 5.

\section{Problem Statement}

The electrohydraulic system that we will deal with in this paper is depicted in Figure 1 and modeled by the dynamical system (1). It has been shown in [34] that, for the symmetrical piston with equal surfaces $S_{1}$ and $S_{2}$ and assuming equal volume flow passing through (geometrically) identical ports, we can describe the system by three variable states where a differential pressure state substitutes the pressure of each chamber. This decrease in the system dimension ensures the observability when the system output is the piston position. Consider

$$
\begin{aligned}
& \dot{x}_{1}=\frac{4 B}{V_{t}}\left(k u \sqrt{P_{d}-\operatorname{sign}(u) x_{1}}-\frac{\alpha x_{1}}{1+\gamma|u|}-S x_{2}\right), \\
& \dot{x}_{2}=\frac{1}{m_{t}}\left(S x_{1}-b x_{2}-\left(k_{l}+\Delta k_{l}\right) x_{3}\right), \\
& \dot{x}_{3}=x_{2}+d(t),
\end{aligned}
$$

where $x_{1}=P_{1}-P_{2}$ denotes the difference in pressure inside the two chambers of the cylinder, $x_{2}$ and $x_{3}$, respectively, denote the velocity and the position of the rod, and $|d(t)|<d_{\max }$ is a bounded constant or slowly varying external perturbation. In fact, from Newton's law, a constant force perturbation leads to a constant acceleration. Thus, the velocity perturbation may be interpreted as the result of an impulsive force that acts abruptly on the system. $m_{t}=m+m_{0}$ is the total mass of the rod and the load, $V_{t}=V_{1}+V_{2}$ is the total volume of the cylinder, and $P_{d}=P_{s}-P_{r}$ is the pressure difference between the supply pressure $P_{s}$ (pressure of the pump) and the return pressure $P_{r}$ (atmospheric pressure). $k_{l}$ is the spring stiffness constant with an uncertainty $\Delta k_{l}$ and $b$ is the friction coefficient. The system parameters used for simulations are as follows: $B=2.2 \times 10^{9} \mathrm{~Pa}, P_{s}=300 \times 10^{5} \mathrm{~Pa}$,
$P_{r}=10^{5} \mathrm{~Pa}, m_{0}=50 \mathrm{~kg}, S=1.5 \times 10^{-3} \mathrm{~m}^{2}, V_{t}=9 \times 10^{-4} \mathrm{~m}^{3}$, $m=20 \mathrm{~kg}, b=590 \mathrm{~kg} / \mathrm{s}, k_{l}=125000 \mathrm{~N} / \mathrm{m}, k=3.62 \times$ $10^{-5} \mathrm{~m}^{3} \mathrm{~s}^{-1} \mathrm{~A}^{-1} \mathrm{~Pa}^{-1 / 2}, \alpha=4.1816 \times 10^{-12} \mathrm{~m}^{3} \mathrm{~s}^{-1} \mathrm{~Pa}^{-1}$, and $\gamma=8571$ with $\alpha$ and $\gamma$ being intrinsic constants modeling the leakage within the servovalve [2].

The most difficult aspect in this model is the existence of a mismatched perturbation as well as a mismatched parameter uncertainty. In addition, the leakage model includes nonlinearity with respect to the control signal $u$. To deal with this problem, we neglect the leakage term in the design but we consider it in simulation and consider the system as a switching system between two models. The switching aspect makes the use of the sliding mode approach a good candidate to design a controller $u$ that can drive the rod position to a constant reference position $x_{3 \text { ref }}$.

2.1. First-Order SMC. The SMC design consists of two phases. In the first phase the sliding surface is designed such that the system is asymptotically stable when it is confined to it and in the second phase a switching controller is designed to ensure the existence of the sliding mode. Our idea consists in viewing the sliding surface design as a special case of backstepping design. Therefore, at sliding mode, $\sigma(x)=0$ means $x_{1}=p(x)$ and $x_{1}$ can be viewed as a virtual controller to subsystem ((2)-(3)) which describes the system behavior on the sliding surface.

Thus, should we choose a linear virtual controller,

$$
p(x)=\frac{1}{S}\left(k_{l} x_{3 \mathrm{ref}}-C_{2} x_{2}-C_{3}\left(x_{3}-x_{3 \mathrm{ref}}\right)\right),
$$

we get the sliding surface

$$
\sigma(x)=S x_{1}+C_{2} x_{2}+C_{3}\left(x_{3}-x_{3 \mathrm{ref}}\right)-k_{l} x_{3 \mathrm{ref}} .
$$

In sliding mode and if uncertainty and perturbations are neglected, the system is a second dimensional linear system with the characteristic equation

$$
s^{2}+\frac{C_{2}+b}{m_{t}} s+\frac{C_{3}+k_{l}}{m_{t}}=0 .
$$

Using the pole placement method and imposing a stable multiple pole at $s=-\lambda$, we can determine the control parameters $C_{2}$ and $C_{3}$ :

$$
\begin{aligned}
& C_{2}=2 \lambda m_{t}-b, \\
& C_{3}=\lambda^{2} m_{t}-k_{l} .
\end{aligned}
$$

Eventually, we obtain an exponentially stable system if we can guarantee the attractivity of the sliding surface $\sigma(x)=$ 0 . Indeed, the attractivity condition $\sigma(x) \dot{\sigma}(x)<0$ will be satisfied if we choose $\dot{\sigma}(x)=-W \operatorname{sign}(\sigma(x))$, where $W>0$ is the sliding gain that should be chosen large enough in order to ensure the attractivity of the surface in presence of perturbation and uncertainty. Using the system model and (5), we can show that $\sigma(x) \dot{\sigma}(x)<0$ is attained if the sliding gain satisfies

$$
W>\left|C_{3} d_{\max }\right|+\frac{4 B S}{V_{t}} \alpha P_{d}+\left|\frac{V_{t} C_{2}}{S m_{t}} \Delta k_{l}\right|,
$$




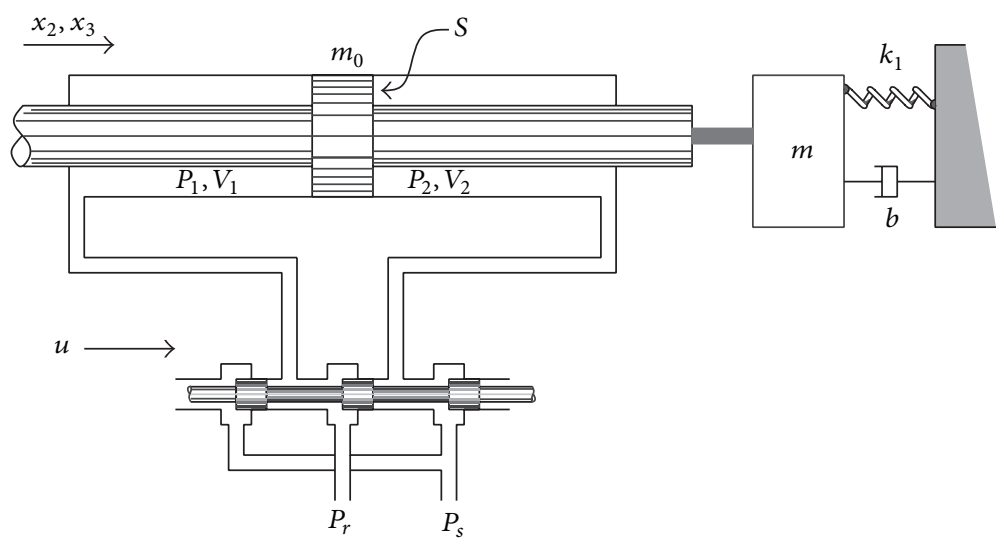

FIGURE 1: Hydraulic servo system controlled using a servovalve.

where $d_{\max }=\max _{t \geq 0} d(t)$. Consequently, by solving $\dot{\sigma}(x)=$ $-W \operatorname{sign}(\sigma(x))$, the control law is expressed as follows:

$$
u(x)= \begin{cases}\frac{N(x)}{\left(4 B S k / V_{t}\right) \sqrt{P_{d}-x_{1}},}, & \text { if } N(x) \leq 0 \\ \frac{N(x)}{\left(4 B S k / V_{t}\right) \sqrt{P_{d}+x_{1}}}, & \text { if } N(x)<0,\end{cases}
$$

where

$$
\begin{aligned}
N(x)= & -W \operatorname{sign}(\sigma(x))-\frac{C_{2}}{m_{t}}\left(S x_{1}-b x_{2}-k_{l} x_{3}\right) \\
& -C_{3} x_{2}+\frac{4 B S^{2}}{V_{t}} x_{2} .
\end{aligned}
$$

Despite the perturbation $d(t)$ and the uncertainty $\Delta k_{l}$, the variable structure controller defined by (9) with the sliding gain $W$ in (8) ensures the existence of sliding mode; however, we can easily deduce that we do not achieve the reference output because when the system behavior is confined to the sliding surface (5) the linear virtual controller does not guarantee any robustness with respect to the perturbation and the uncertainty. Indeed, it can be easily shown that as far as the sliding motion is preserved the system is asymptotically stable if the closed loop eigenvalue is chosen such as

$$
\lambda>\sqrt{\left|\frac{\Delta k_{l}}{m_{t}}\right|}
$$

and in that case the steady state error due to the uncertainty is given by

$$
e_{k_{l}}=\frac{\Delta k_{l}}{m_{t}} \frac{1}{\lambda^{2}+\Delta k_{l} / m_{t}} x_{3 \mathrm{ref}} .
$$

We similarly can show that the steady state error due to the constant perturbation is given by

$$
e_{d}=-\frac{2}{\lambda} d
$$

Figure 2 shows the system behavior with $\lambda=50, d(t)=$ $0.1, \Delta k_{l}=25000$, and $x_{3 \mathrm{ref}}=20 \mathrm{~cm}$. We clearly notice that there is a steady state error of more than $2 \mathrm{~cm}$ at the position output. So the first-order sliding mode is not robust to the mismatched uncertainty and perturbation.
2.2. Second-Order SMC. Since the system is third-order single input, then we may think of designing the higher-order SMC up to second order. Let $\sigma_{h}$ denote the sliding variable defined as

$$
\sigma_{h}=h\left(x_{3}-x_{3 \mathrm{ref}}\right)+x_{2},
$$

where $h>0$ is a strictly positive scalar. We may verify that the relative degree of system ((1)-(3)) together with (14) with respect to the sliding variable $\sigma_{h}$ is constant and equal to two. Thus we have

$$
\ddot{\sigma}_{h}=a_{1}(x, t)+\Delta a_{1}(x, t)+a_{2}(x) u
$$

where $a_{1}(x, t)$ and $a_{2}(x)$ are known functions and $\Delta a_{1}(x, t)$ is an unknown bounded function in terms of $d(t)$ and $\Delta k_{l}$ :

$$
\begin{aligned}
a_{1}(x, t)= & -\frac{4 B S}{m_{t} V_{t}}\left(\alpha x_{1}+S x_{2}\right) \\
& +\left(\frac{h}{m_{t}}-\frac{b}{m_{t}^{2}}\right)\left(S x_{1}-b x_{2}-k_{l} x_{3}\right) \\
& -\frac{k_{l}}{m_{t}} x_{2}, \\
\Delta a_{1}(x, t)= & -\left(\frac{h}{m_{t}}-\frac{b}{m_{t}^{2}}\right) \Delta k_{l} x_{3}-\frac{\Delta k_{l}}{m_{t}} x_{2} \\
& -d(t) \frac{k_{l}+\Delta k_{l}}{m_{t}}, \\
a_{2}(x)= & \begin{cases}\frac{4 B S}{m_{t} V_{t}} k \sqrt{P_{d}-x_{1}} & \text { if } u \geq 0 \\
\frac{4 B S}{m_{t} V_{t}} k \sqrt{P_{d}+x_{1}} & \text { if } u<0 .\end{cases}
\end{aligned}
$$

The solution should be understood in the Filippov sense [35], and the trajectories of the system are supposed to be extendible infinitely in time for any bounded measurable input. 

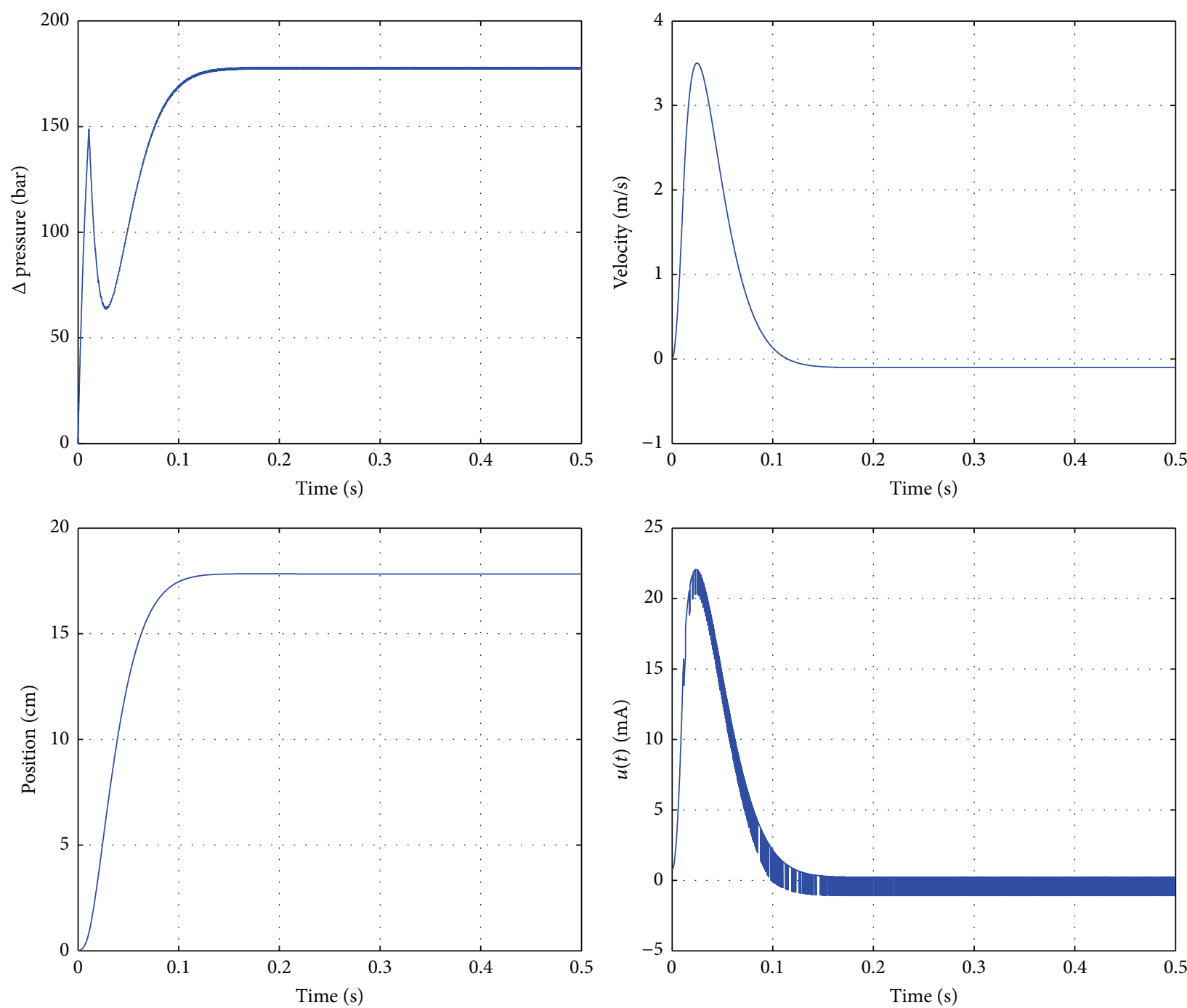

FIGURE 2: The behavior of the system under sliding mode controller defined by (9); $\lambda=50$.

By defining $z_{1}=\sigma_{h}$ and $z_{2}=\dot{\sigma}_{h}$, achieving sliding mode $\sigma_{h}=0$ is equivalent to the finite stabilization of the system:

$$
\begin{aligned}
& \dot{z}_{1}=z_{2}, \\
& \dot{z}_{2}=a_{1}(x, t)+\Delta a_{1}(x, t)+a_{2}(x) u,
\end{aligned}
$$

which hence ideally yields to the sliding set $\sigma_{h}=0$ and $\dot{\sigma}_{h}=0$. Taking into account the practical considerations, the sliding set is defined as follows [27].

Definition 1. Given the sliding variable $\sigma_{h}(x, t)$, the "real second-order sliding set" associated with ((1)-(3)) is defined as

$$
s_{T_{e}}=\left\{x \in \frac{\chi}{\left|\sigma_{h}\right|} \leq k_{1} T_{e}^{2},\left|\dot{\sigma}_{h}\right| \leq k_{2} T_{e}\right\},
$$

where $T_{e}$ is the finite sampling time (fixed at $T_{e}=20 \mu \mathrm{s}$ in the sequel) and $k_{1}$ and $k_{2}$ are positive constants.
Definition 2. Consider the nonempty real second-order sliding set $s_{T_{e}}$ given in (18), and assume that it is locally an integral set in the Filippov sense. The corresponding behavior of system ((1)-(3)) satisfying (18) is called "real second-order sliding mode" with respect to $\sigma_{h}(x, t)$ [27].

The variable structure control law $u$ can be chosen as follows:

$$
\begin{aligned}
u= & \frac{1}{a_{2}(x)}\left(-a_{1}(x, t)-K_{1} z_{1}-K_{2} z_{2}-W_{1} \operatorname{sign}\left(z_{1}\right)\right. \\
& \left.-W_{2} \operatorname{sign}\left(z_{2}\right)\right),
\end{aligned}
$$

where all the controller gains $K_{1}, K_{2}, W_{1}$, and $W_{2}$ are strictly positive. Applying controller (19) yields to

$$
\begin{aligned}
{\left[\begin{array}{l}
\dot{z}_{1} \\
\dot{z}_{2}
\end{array}\right]=} & {\left[\begin{array}{cc}
0 & 1 \\
-K_{1} & -K_{2}
\end{array}\right]\left[\begin{array}{l}
z_{1} \\
z_{2}
\end{array}\right] } \\
& +\left[\begin{array}{cc}
0 & 0 \\
-W_{1} & -W_{2}
\end{array}\right]\left[\begin{array}{l}
\operatorname{sign}\left(z_{1}\right) \\
\operatorname{sign}\left(z_{2}\right)
\end{array}\right]-\left[\begin{array}{l}
0 \\
1
\end{array}\right] \Delta a_{1}(x, t)
\end{aligned}
$$


which can be written in the following compact form:

$$
\dot{Z}=A_{K} Z+A_{W} \operatorname{sign}(z)-B \Delta a(x, t),
$$

where $A_{K}=\left[\begin{array}{cc}0 & 1 \\ -K_{1} & -K_{2}\end{array}\right], A_{W}=\left[\begin{array}{cc}0 & 0 \\ -W_{1} & -W_{2}\end{array}\right]$, and $B=\left[\begin{array}{l}0 \\ 1\end{array}\right]$.

We can determine the control parameters $K_{1}$ and $K_{2}$ such that the characteristic equation of $A_{K}$ has two equal eigenvalues at $s=-\lambda$ :

$$
\begin{gathered}
K_{1}=\lambda^{2}, \\
K_{2}=2 \lambda, \\
\lambda>0 .
\end{gathered}
$$

Since $A_{K}$ is a Hurwitz matrix, then it satisfies the Lyapunov function $A_{K}^{T} P+P A_{K}=-Q$, where $P$ and $Q$ are some positive definite matrices. To determine the gains $W_{1}$ and $W_{2}$ we define the following Lyapunov function candidate for system (20):

$$
V(Z)=Z^{T} P Z
$$

Its time derivative in the direction of system (20) trajectories is given by

$$
\begin{aligned}
\dot{V} & =\dot{Z}^{T} P Z+Z^{T} P \dot{Z} \\
& =-Z^{T} Q Z+2 Z^{T} P A_{W} \operatorname{sign}(Z)-2 Z^{T} P B \Delta a(x, t) .
\end{aligned}
$$

If we choose $P_{22} W_{1}=P_{12} W_{2}$ then $P A_{W}$ is a negative definite matrix and we have

$$
\begin{aligned}
\dot{V}< & -Z^{T} Q Z+2 \lambda_{\max }\left(P A_{W}\right)\|Z\|_{1} \\
& +2\|Z\|_{1} \lambda_{\min }(P)\|B\|_{1}|\Delta a(x, t)|<0
\end{aligned}
$$

provided that $W_{1}$ and $W_{2}$ are also chosen such that

$$
-\lambda_{\text {max }}\left(P A_{W}\right)>\lambda_{\text {min }}(P)\left|\Delta a_{1}(x, t)\right|,
$$

where $\lambda_{\max }(\cdot)$ and $\lambda_{\min }(\cdot)$ are, respectively, the largest and least eigenvalues of the matrix.

From Figure 3, we can notice that the second-order SMC achieves a better performance than the first-order SMC. However, the robustness with respect to the constant perturbation is not guaranteed. Indeed, in sliding mode, we have $\sigma_{h}=0$; thus $x_{2}=-h\left(x_{3}-x_{3 \text { ref }}\right)=-h e_{3}$ and hence on the sliding set $\sigma_{h}=0$ we get

$$
\dot{e}_{3}=-h e_{3}+d(t)
$$

which is a first-order nonautonomous system with a steady state value equal to $d(t) / h$. Therefore, for the constant perturbation $d(t)=0.1$, the steady state error is as expected and delineated in Figure $3 ; x_{3}-x_{3 \mathrm{ref}}=0.1 \mathrm{~cm}$. When increasing the value of $h$, the variable structure gains $W_{1}$ and $W_{2}$ should be increased, thus accentuating the chattering phenomenon which was attenuated by the use of the secondorder sliding mode.

The boundedness of $x_{1}$ and $x_{2}$ is ensured since $\dot{V}<0$ and $V(Z)$ depends on $z_{1}$ and $z_{2}$ which in turn depend on $x_{1}, x_{2}$, and $x_{3}$.

\section{Sliding Mode Controller with Nonlinear Surface}

To overcome the problem of mismatched perturbation and uncertainty, we suggest in this section designing a sliding surface $\sigma(x)$ based on the backstepping method and using robust variable structure virtual controller.

In Section 2.1, the sliding surface $\sigma(x)=0$ was obtained from the design of the linear controller $x_{1}=p(x)$ for subsystem ((2)-(3)). To ensure robustness with respect to the parametric uncertainty, a variable structure virtual controller $x_{1}=p(x)$ is designed by choosing a sliding surface $\sigma_{1}\left(x_{2}, x_{3}\right)$ and requiring its attractivity by imposing

$$
\dot{\sigma}_{1}\left(x_{2}, x_{3}\right)=-W_{1} \operatorname{sign}\left(\sigma_{1}\left(x_{2}, x_{3}\right)\right) \text {. }
$$

Therefore, the virtual controller $x_{1}=p(x)$ is obtained by solving (28) and the sliding surface $\sigma(x)=x_{1}-p(x)$. However, when sliding on $\sigma_{1}\left(x_{2}, x_{3}\right)$ is achieved, we get $\sigma_{1}\left(x_{2}, x_{3}\right)=0$ which means $x_{2}=v\left(x_{3}\right)$ and thus in sliding mode we have

$$
\dot{x}_{3}=v\left(x_{3}\right)+d(t) .
$$

Again to ensure asymptotic convergence of $x_{3}(t)$ to $x_{3 \mathrm{ref}}$ a simple linear proportional term $v\left(x_{3}\right)=-C\left(x_{3}-x_{3 \mathrm{ref}}\right)$ is not satisfactory, but a variable structure term can guarantee the required convergence. Indeed, with

$$
v\left(x_{3}\right)=-W_{3}\left(x_{3}-x_{3 \mathrm{ref}}\right)-W_{2} \operatorname{sign}\left(x_{3}-x_{3 \mathrm{ref}}\right),
$$

where the gains are chosen such that $W_{2}>d_{\max }$ and $W_{3}>0$, we may easily show the convergence of $x_{3}(t)$ to $x_{3 \text { ref }}$ as far as the sliding surface

$$
\begin{aligned}
\sigma_{1}\left(x_{2}, x_{3}\right)= & x_{2}+W_{3}\left(x_{3}-x_{3 \mathrm{ref}}\right) \\
& +W_{2} \operatorname{sign}\left(x_{3}-x_{3 \mathrm{ref}}\right)
\end{aligned}
$$

is attractive.

When attempting to achieve the attractivity of $\sigma_{1}\left(x_{2}, x_{3}\right)$ by imposing (28), we face the attempt to differentiate a discontinuous function. Although this is mathematically impossible, we can overcome the problem from an engineering point of view by either replacing the discontinuous signum function with a smoother saturation function or directly considering that the derivative of the signum function is the Dirac impulse $(\delta(x))$ which is zero everywhere except at an isolated single point. Indeed, in engineering realization using a processor and discretization process, the isolated discontinuities, especially when they are few, can easily be avoided and would not cause any problems. Therefore, from (28), we have

$$
\begin{aligned}
& \frac{1}{m_{t}}\left(S x_{1}-b x_{2}-k_{l} x_{3}\right)+W_{3} x_{2}+W_{2} x_{2} \delta\left(x_{3}-x_{3 \mathrm{ref}}\right) \\
& \quad=-W_{1} \operatorname{sign}\left(\sigma_{1}\left(x_{2}, x_{3}\right)\right)
\end{aligned}
$$

and the sliding surface $\sigma(x)$ becomes

$$
\begin{aligned}
\sigma(x)= & S x_{1}+\left(m_{t} W_{3}+m_{t} W_{2} \delta\left(x_{3}-x_{3 \mathrm{ref}}\right)-b\right) x_{2} \\
& -k_{l} x_{3}+m_{t} W_{1} \operatorname{sign}\left(\sigma_{1}\left(x_{2}, x_{3}\right)\right) .
\end{aligned}
$$



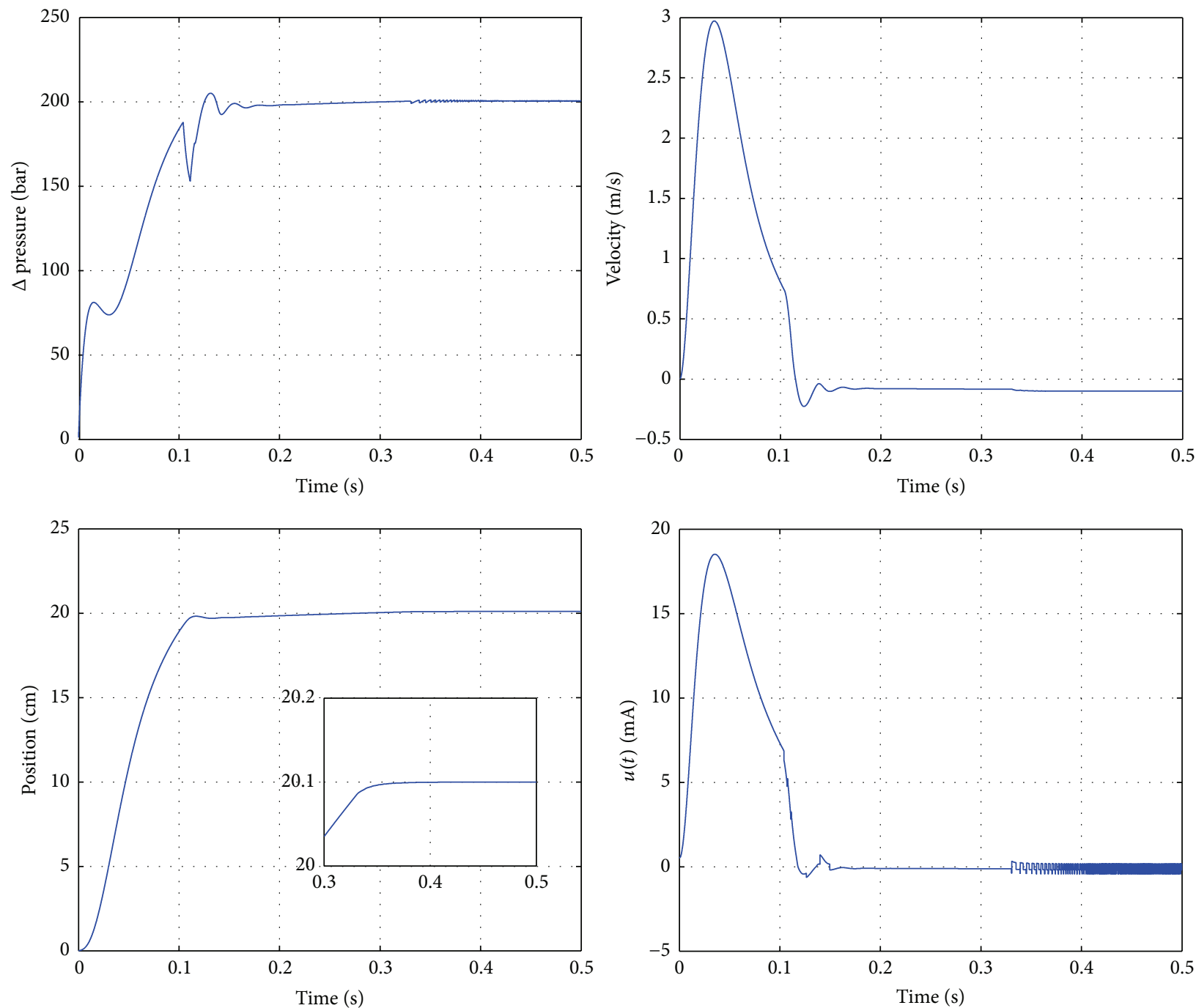

FIgURE 3: Behavior of system under second-order sliding mode controller (19); $\lambda=50$ and $h=100$.

Finally, by imposing $\dot{\sigma}(x)=-W \operatorname{sign}(\sigma(x))$, the attractivity condition $\sigma(x) \dot{\sigma}(x)<0$ is satisfied. The choice of the surface $\sigma(x)$ and its imposed derivative lead to the following controller:

$$
u(x)= \begin{cases}\frac{N_{d}(x)}{\left(4 B S k / V_{t}\right) \sqrt{P_{d}-x_{1}},}, & \text { if } N_{d}(x) \geq 0 \\ \frac{N_{d}(x)}{\left(4 B S k / V_{t}\right) \sqrt{P_{d}+x_{1}}}, & \text { if } N_{d}(x)<0\end{cases}
$$

with

$$
\begin{aligned}
N_{d}(x)= & -W \operatorname{sign}(\sigma(x))-m_{t} W_{1} \delta\left(\sigma_{1}(x)\right) \\
& +\left(\frac{4 B S \alpha}{V t}+\frac{b S}{m_{t}}-S W_{4}\right) x_{1}
\end{aligned}
$$

$$
\begin{aligned}
& +\left(\frac{4 B S^{2}}{V t}-\frac{b^{2}}{m_{t}}+k_{l}+b W_{4}\right) x_{2} \\
& +\left(k_{l} W_{4}-\frac{b k_{l}}{m_{t}}\right) x_{3}
\end{aligned}
$$

where the derivative of the Dirac impulse is considered as zero and the sliding gain $W$ should be chosen such that the attractivity occurs in presence of uncertainty and perturbation:

$$
W>\left|\frac{b V_{t}}{S m_{t}} \Delta k_{l}\right|+\left|\frac{V_{t}}{S} W_{3} \Delta k_{l}\right|+\left|k_{l} d_{\max }\right| .
$$

From Figure 4, we can notice clearly that we have attained our aim to drive the hydraulic servo system to the reference position. Nevertheless, due to the nested sliding modes, the chattering phenomenon was emphasized. 

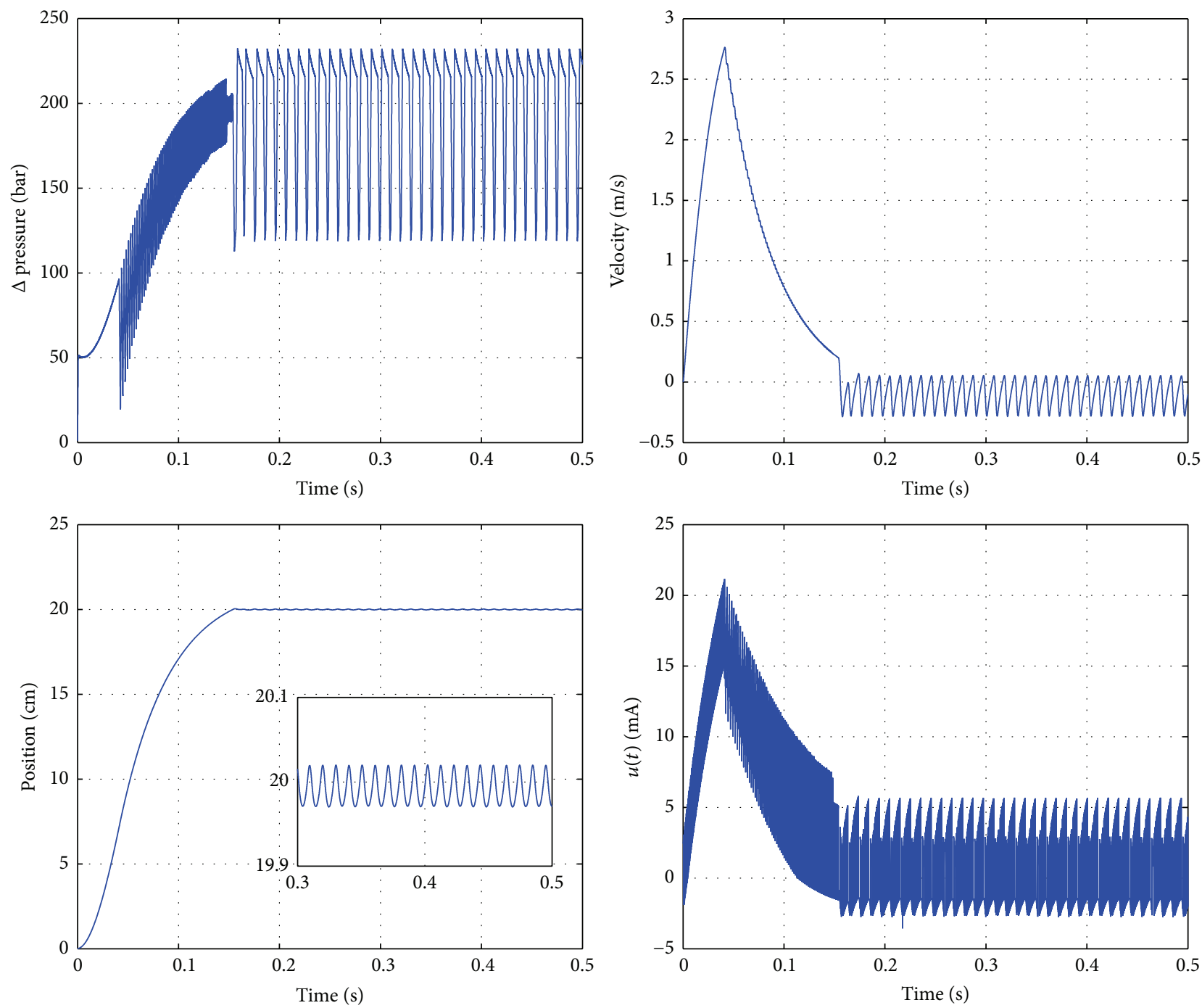

FiguRE 4: Behavior of system under sliding mode controller using nonlinear surface defined by (33).

In order to attenuate it and to avoid the mathematical problem of taking the derivative of the signum function we have used a smooth saturation function $\operatorname{sign}(x) \simeq \tanh (\mu x)$ for a sufficiently high positive value $\mu>0$. The results depicted in Figure 5 show that the use of the smooth function helped to achieve the reference value in presence of mismatched uncertainty and perturbation with attenuated chattering.

\section{Sliding Mode Observer Design}

As we can notice, the controller conceived in the foregoing section uses all three state variables. However, measuring the differential pressure $\Delta P=x_{1}$ is a costly task and requires high technology procedure to avoid additional leakage. To remedy this situation, we propose in this section designing a sliding mode observer that may estimate the required states that are then used to construct the controller.
Let us consider the observer model given in (37) and inferred from the step-by-step observer presented in $[36,37]$ :

$$
\begin{aligned}
\dot{z}_{1}= & \frac{4 B}{V_{t}}\left(k u \sqrt{P_{d}-\operatorname{sign}(u) \widetilde{z}_{1}}-\frac{\alpha \widetilde{z}_{1}}{1+\gamma|u|}-S \widetilde{z}_{2}\right) \\
& +L_{1} \operatorname{sign}\left(\widetilde{z}_{1}-z_{1}\right), \\
\dot{z}_{2}= & \frac{1}{m_{t}}\left(S z_{1}-b \widetilde{z}_{2}-k_{l} z_{3}\right)+L_{2} \operatorname{sign}\left(\widetilde{z}_{2}-z_{2}\right), \\
\dot{z}_{3}= & z_{2}+L_{3} \operatorname{sign}\left(x_{3}-z_{3}\right),
\end{aligned}
$$

where $L_{1}, L_{2}$, and $L_{3}$ are the observer gain and $\widetilde{z}_{1}$ and $\widetilde{z}_{2}$ are defined as

$$
\begin{aligned}
& \widetilde{z}_{1}=z_{1}+\frac{k_{l}}{S}\left(x_{3}-z_{3}\right)+\frac{m_{t}}{S} L_{2} \operatorname{sign}\left(\widetilde{z}_{2}-z_{2}\right), \\
& \widetilde{z}_{2}=z_{2}+L_{3} \operatorname{sign}\left(x_{3}-z_{3}\right) .
\end{aligned}
$$



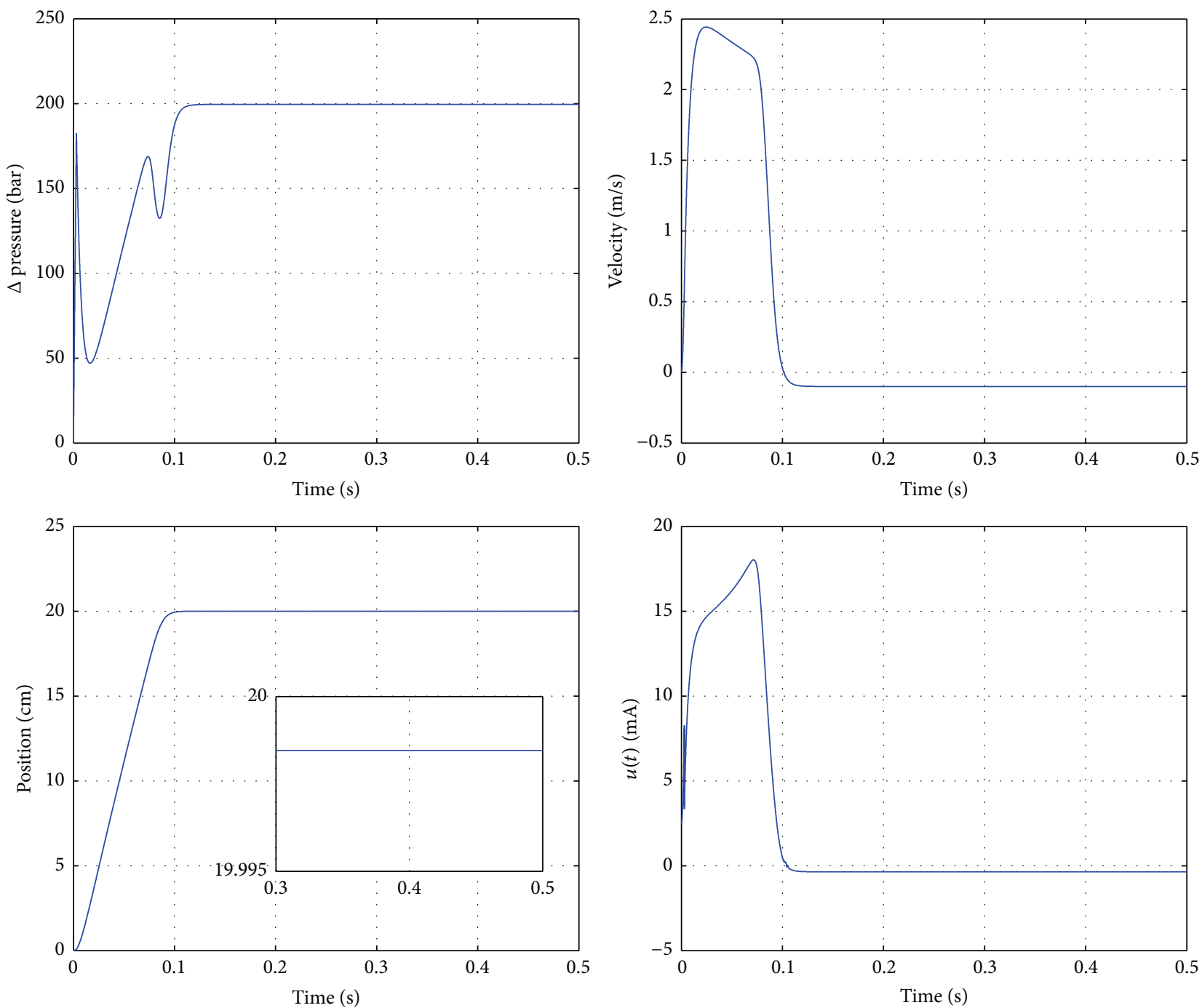

FIGURE 5: Behavior of system under sliding mode controller using nonlinear surface defined by (33) and a smooth saturation function tanh(·).

To prove the efficiency of the observer and the fact that the estimated states based controller can also achieve accurate positioning in presence of perturbation and uncertainty, we will proceed by a step-by-step proof.

Step 1. Let $e_{3}=x_{3}-z_{3}$ and let $e_{2}=x_{2}-z_{2}$; from (3) and (39) the error dynamics are expressed as

$$
\dot{e}_{3}=e_{2}+d(t)-L_{3} \operatorname{sign}\left(e_{3}\right) .
$$

Thus, if $L_{3}$ is chosen such that

$$
L_{3}>\sup _{t>0}\left\{e_{2}(t)+d(t)\right\}
$$

then a sliding mode is established at the observer sliding surface $e_{3}=0$ within a finite time. Moreover, at sliding mode, we obtain $\dot{e}_{3}=0$ and thus from (41) we have

$$
0=x_{2}-z_{2}+d(t)-L_{3} \operatorname{sign}\left(e_{3}\right) ;
$$

that is,

$$
x_{2}+d(t)=z_{2}+L_{3} \operatorname{sign}\left(e_{3}\right)=\widetilde{z}_{2}
$$

Now, if the sliding surface $\sigma_{1}$ of the nonlinear surface based SMC is expressed in terms of the estimated state $\widetilde{z}_{2}$,

$$
\begin{aligned}
\sigma_{1}\left(\widetilde{z}_{2}, x_{3}\right)= & \widetilde{z}_{2}+W_{3}\left(x_{3}-x_{3 \mathrm{ref}}\right) \\
& +W_{2} \operatorname{sign}\left(x_{3}-x_{3 \mathrm{ref}}\right),
\end{aligned}
$$

then, by using (3), (44), and (45), the position dynamics are given by

$$
\dot{x}_{3}=-W_{3}\left(x_{3}-x_{3 \mathrm{ref}}\right)-W_{2} \operatorname{sign}\left(x_{3}-x_{3 \mathrm{ref}}\right) .
$$

Therefore, within a finite time we obtain $x_{3}=x_{3 \text { ref }}$.

Step 2. Let $e_{1}=x_{1}-z_{1}$; from (2) and (38) the error dynamics are expressed as

$$
\begin{aligned}
\dot{e}_{2}= & \frac{1}{m_{t}}\left(S e_{1}-b e_{2}-b L_{3} \operatorname{sign}\left(e_{3}\right)-k_{l} e_{3}\right)-\frac{\Delta k_{l}}{m_{t}} x_{3} \\
& -L_{2} \operatorname{sign}\left(\widetilde{z}_{2}-z_{2}\right) .
\end{aligned}
$$


Thus, if $L_{2}$ is chosen such that

$$
L_{2}>\frac{1}{m_{t}}\left|\Delta k_{l} x_{3}+S e_{1}+b d_{\max }\right|
$$

then we can deduce that $e_{2}+d$ tend to zero and hence $z_{2}$ tend to $x_{2}+d$. That is, the observer will estimate the velocity with the constant perturbation. Moreover, when the error dynamics are sliding on $e_{3}=0$ and $e_{2}+d=0$, then $\dot{e}_{2}=0$ and we get

$$
\widetilde{z}_{1}=x_{1}+\frac{b}{S} e_{2}-\frac{\Delta k_{l}}{S} x_{3}
$$

That is, the observer will estimate the differential pressure with a constant difference proportional to the perturbation and the uncertainty. Now, if the controller sliding surface $\sigma$ is expressed using the observer state variables,

$$
\begin{aligned}
\sigma(z)= & S \widetilde{z}_{1}+\left(m_{t} W_{3}+m_{t} W_{2} \delta\left(x_{3}-x_{3 \mathrm{ref}}\right)-b\right) \tilde{z}_{2} \\
& -k_{l} z_{3}+m_{t} W_{1} \operatorname{sign}\left(\sigma_{1}\left(\widetilde{z}_{2}, x_{3}\right)\right),
\end{aligned}
$$

then, at sliding mode of the controller $\dot{\sigma}(z)=0$, the velocity dynamics are given by

$$
\dot{x}_{2}=-W_{3}\left(x_{2}+d\right)-W_{1} \operatorname{sign}\left(\sigma_{1}\left(\widetilde{z}_{2}, x_{3}\right)\right) .
$$

Hence the velocity of the system rod will tend to $-d$.

Step 3. Finally, the differential pressure error dynamics can be roughly expressed as

$$
\dot{e}_{1}=f_{1}(x)-f_{1}(z)-L_{1} \operatorname{sign}\left(e_{1}+\frac{b}{S} e_{2}-\frac{\Delta k_{l}}{S} x_{3}\right) ;
$$

if the system is already sliding on the surfaces $x_{3}=x_{3 \text { ref }}$ and $e_{2}=-d$ then by choosing $L_{1}>\left|f_{1}(x)-f_{1}(z)\right|$ the differential pressure is estimated with the constant difference $-(b / S) d+$ $\Delta V_{t}$.

Figure 6 shows the convergence of the observer state $z_{3}$ to $x_{3}$ although they are starting from different initial conditions; indeed, the observer is starting at rod position $10 \mathrm{~cm}$ whereas the system is starting at the origin. As expected from the above analysis, $z_{2}$ tends to $x_{2}+d$ and $z_{1}$ tends to $x_{1}$ with a constant difference of 33 bar. The observer gains are chosen as $L_{1}=1000, L_{2}=100$, and $L_{3}=1$. In Figure 7, the observer and system behaviors are shown with the controller being calculated using the estimated states. The observer initial position is $-10 \mathrm{~cm}$.

\section{Simulation Results Analysis}

The controllers designed in this paper used the sliding mode theory which is the most used approach to deal with systems running under uncertainty conditions. However, we have seen in the second section that the first-order sliding mode controller with a linear sliding surface is not robust with respect to perturbation and mismatched uncertainty. In fact, by using the fact that on the sliding surface the system behaves in a similar way to a linear second-order system, it can be
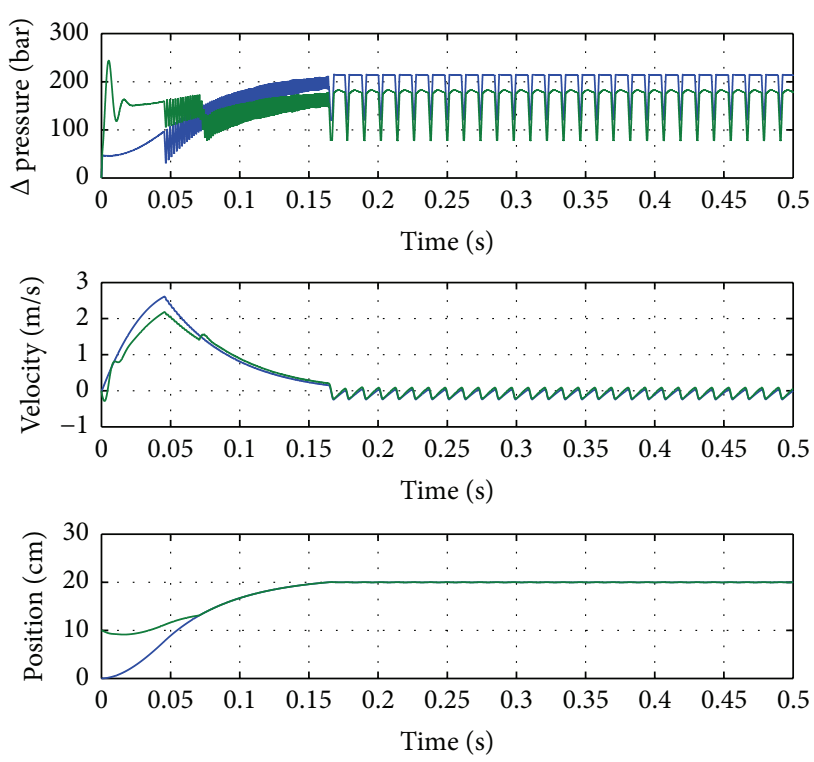

Figure 6: Behavior of the observer and the hydraulic servo system controlled with sliding mode controller with states feedback.
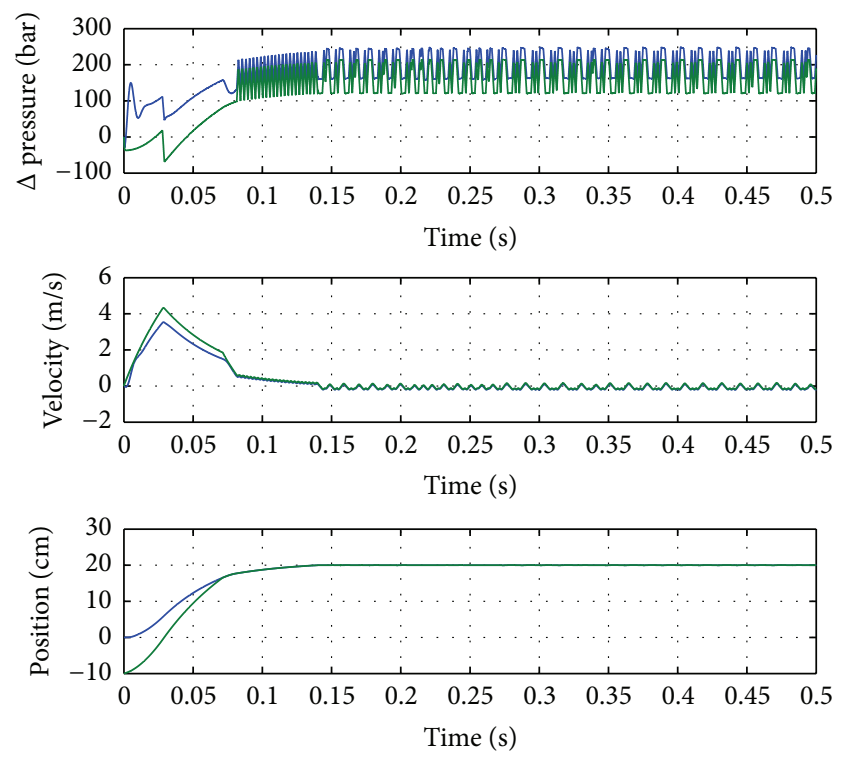

FIGURE 7: Behavior of the observer and the hydraulic servo system controlled with sliding mode controller with estimated states feedback.

easily shown that as far as the sliding motion is preserved, the system is asymptotically stable if the closed loop eigenvalues are chosen as in (11) and thus the steady state error due to the uncertainty is expressed by (12). Also, the steady state error due to the constant perturbation is given by (13).

Therefore, the steady state error gets smaller as the closed loop eigenvalues have a larger amplitude. This is illustrated by the simulation results delineated in Figure 2 where $\lambda=50$ and the total error is $2.46 \mathrm{~cm}$.

To circumvent the problem, we have suggested a secondorder sliding mode controller. Applying this controller, we 
can notice that it achieves a better performance than the first SMC. In fact, the second-order SMC outperforms the firstorder SMC in sense of robustness with respect to mismatched perturbation but it cannot guarantee the robustness with respect to the constant perturbation. The steady state error due to the perturbation is equal to $d(t) / h$ as demonstrated previously. When the perturbation $d(t)=0.1$ the error is equal to $0.1 \mathrm{~cm}$ as delineated in Figure 3. If we increase the value of $h$, we should also increase the value of the variable structure gains $W_{1}$ and $W_{2}$. So we obtain a chattering phenomenon.

To overcome the problem of mismatched perturbation and uncertainty, we have suggested a sliding mode controller with nonlinear surface. The idea is based on the backstepping method and using a robust variable structure virtual controller. The obtained results achieved robustness with respect to parameter uncertainty and perturbation. The zoomed curve on Figure 4 shows that we have attained our aim to drive the hydraulic servo system to a reference position but with a chattering phenomenon. So to attenuate this problem we suggest substituting the discontinuous function $\operatorname{sign}(x)$ with a smooth saturation function $\tanh (\mu x)$ for sufficiently high positive value $\mu>0$. Owing to this smooth function, we can achieve the reference value in presence of mismatched uncertainty and perturbation with attenuated chattering.

Finally, in Section 4, we designed a sliding mode observer in order to estimate the required states. The efficiency of this observer is proved mathematically and also by simulations presented in Figures 6 and 7.

Compared to other methods such as that presented in [17], which is based on adaptive approach to achieve position control, we notice that our method provides faster response since the adaptive controller proposed therein attempts to estimate the mismatched nonlinear uncertainty. Indeed, the rod makes a displacement of $30 \mathrm{~cm}$ within more than $0.8 \mathrm{~s}$, whereas with our method a maximum of $0.2 \mathrm{~s}$ will be needed to make the same displacement. In [21], the authors presented a controller based on variable structure PID to drive the hydraulic system position. Although fast response has been achieved, which is comparable to our results, the good robustness was obtained since the uncertainties and the perturbation were matched with the controller. In our case, the robustness against the mismatched character of the perturbation and uncertainty presented the main challenge to take. In [26], authors obtained comparable results to those presented in this paper using integral sliding mode controller with realizable reference compensation applied to an asymmetric piston.

\section{Conclusion}

In this paper, we developed several controllers based on the sliding mode theory. Our aim was to control the position of a hydraulic servo system piston in presence of mismatched uncertainty and perturbation. We have shown that a first-order sliding mode controller did not achieve any robustness. Next we have developed a second-order sliding mode controller that has shown robustness with respect to parametric uncertainty but was not robust to the perturbation. Finally, we have suggested a sliding mode controller based on a nonlinear sliding surface. The design is based on the backstepping method where on each step a variable structure virtual controller design leads to the design of the sliding surface. This controller emphasized the chattering phenomenon due to the nested sliding modes. As a remedy, we suggested substituting the discontinuous function with a smooth saturation function. Eventually, we have designed a robust sliding observer in order to substitute the unmeasured states with their estimates. A step-by-step proof has shown that the controller issued from the estimated states achieved the position tracking.

\section{Conflict of Interests}

The authors declare that there is no conflict of interests regarding the publication of this paper.

\section{References}

[1] H. E. Merritt, Hydraulic Control Systems, John Wiley \& Sons, New York, NY, USA, 1967.

[2] M. Feki and E. Richard, "Including leakage flow in the servovalve static model," International Journal of Modelling and Simulation, vol. 25, no. 1, pp. 4004-4009, 2005.

[3] A. Alleyne, R. Liu, and H. Wright, "On the limitations of force tracking control for hydraulic active suspensions," in Proceedings of the American Control Conference (ACC '98), vol. 1, pp. 43-47, June 1998.

[4] Y. Cheng and B. L. R. De Moor, "Robustness analysis and control system design for a hydraulic servo system," IEEE Transactions on Control Systems Technology, vol. 2, no. 3, pp. 183-197, 1994.

[5] M. Feki, E. Richard, and F. Gomes Almeida, "Commande en effort d'un vèrin hydraulique par linèarization entrèe/sortie," in Journèes Doctorales d'Automatiques (JDA '99), pp. 181-184, Nancy-France, 1999.

[6] H. Hahn, A. Piepenbrink, and K.-D. Leimbach, "Input/output linearization control of an electro servo-hydraulic actuator," in Proceedings of the 3rd IEEE Conference on Control Applications, pp. 995-1000, August 1994.

[7] M. Jovanovic, "Nonlinear control of an electrohydraulic velocity servosystem," in Proceedings of the 2002 American Control Conference, vol. 1, pp. 588-593, 2002.

[8] G. A. Sohl and J. E. Bobrow, "Experiments and simulations on the nonlinear control of a hydraulic servosystem," IEEE Transactions on Control Systems Technology, vol. 7, no. 2, pp. 238-247, 1999.

[9] A. G. Alleyne and R. Liu, "Systematic control of a class of nonlinear systems with application to electrohydraulic cylinder pressure control," IEEE Transactions on Control Systems Technology, vol. 8, no. 4, pp. 623-634, 2000.

[10] M. A. Avila, A. G. Loukianov, and E. N. Sanchez, "Electrohydraulic actuator trajectory tracking," in Proceedings of the American Control Conference (AAC '04), vol. 3, pp. 2603-2608, IEEE, Boston, Mass, USA, July 2004.

[11] A. Bonchis, P. I. Corke, D. C. Rye, and Q. P. Ha, "Variable structure methods in hydraulic servo systems control," Automatica, vol. 37, no. 4, pp. 589-595, 2001.

[12] M. Jerouane and F. Lamnabhi-Lagarrigue, "A new robust sliding mode controller for a hydraulic actuator," in Proceedings of the 
40th IEEE Conference on Decision and Control (CDC '01), vol. 1, pp. 908-913, December 2001.

[13] H.-M. Chen, J.-C. Renn, and J.-P. Su, "Sliding mode control with varying boundary layers for an electro-hydraulic position servo system," The International Journal of Advanced Manufacturing Technology, vol. 26, no. 1-2, pp. 117-123, 2005.

[14] J. M. Zheng, S. D. Zhao, and S. G. Wei, "Application of selftuning fuzzy PID controller for a SRM direct drive volume control hydraulic press," Control Engineering Practice, vol. 17, no. 12, pp. 1398-1404, 2009, Special Section: The 2007 IFAC Symposium on Advances in Automotive Control.

[15] A. Aly, "Pid parameters optimization using genetic algorithm technique for electrohydraulic servo control system," Intelligent Control and Automation, vol. 2, no. 2, pp. 69-76, 2011.

[16] B. Yao, F. Bu, and G. T. C. Chiu, "Nonlinear adaptive robust control of electro-hydraulic servo systems with discontinuous projections," in Proceedings of the 37th IEEE Conference on Decision and Control (CDC '98), pp. 2265-2270, December 1998.

[17] B. Yao, F. Bu, J. Reedy, and G. T.-C. Chiu, "Adaptive robust motion control of single-rod hydraulic actuators: theory and experiments," IEEE/ASME Transactions on Mechatronics, vol. 5, no. 1, pp. 79-91, 2000.

[18] K. K. Ahn and Q. T. Dinh, "Self-tuning of quantitative feedback theory for force control of an electro-hydraulic test machine," Control Engineering Practice, vol. 17, no. 11, pp. 1291-1306, 2009.

[19] E. Kolsi Gdoura, M. Feki, and N. Derbel, "Sliding mode control of a hydraulic servo system position using adaptive sliding surface and adaptive gain," International Journal of Modelling, Identification and Control, vol. 23, pp. 211-219, 2015.

[20] C. Guan and S. Pan, "Adaptive sliding mode control of electrohydraulic system with nonlinear unknown parameters," Control Engineering Practice, vol. 16, no. 11, pp. 1275-1284, 2008.

[21] D. Liu, Z. Tang, and Z. Pei, "Variable structure compensation PID control of asymmetrical hydraulic cylinder trajectory tracking," Mathematical Problems in Engineering, vol. 2015, Article ID 890704, 9 pages, 2015.

[22] A. G. Loukianov, J. Rivera, Y. V. Orlov, and E. Y. Morales Teraoka, "Robust trajectory tracking for an electrohydraulic actuator," IEEE Transactions on Industrial Electronics, vol. 56, no. 9, pp. 3523-3531, 2009.

[23] M. Ye, Q. Wang, and S. Jiao, "Robust $H_{2} / H_{\infty}$ control for the electrohydraulic steering system of a four-wheel vehicle," Mathematical Problems in Engineering, vol. 2014, Article ID 208019, 12 pages, 2014.

[24] W. Shen, J. Jiang, H. R. Karimi, and X. Su, "Observer-based robust control for hydraulic velocity control system," Mathematical Problems in Engineering, vol. 2013, Article ID 689132, 9 pages, 2013.

[25] E. Kolsi-Gdoura, M. Feki, and N. Derbel, "Sliding modebased robust position control of an electrohydraulic system," in Proceedings of the 10th International Multi-Conference on Systems, Signals and Devices (SSD '13), pp. 1-5, March 2013.

[26] E. Kolsi Gdoura, M. Feki, and N. Derbel, "Control of a hydraulic servo system using sliding mode with an integral and realizable reference compensation," Control Engineering and Applied Informatics, vol. 17, pp. 111-119, 2015.

[27] A. Levant, "Sliding order and sliding accuracy in sliding mode control," International Journal of Control, vol. 58, no. 6, pp. 12471263, 1993.
[28] A. Levant, "Higher-order sliding modes, differentiation and output-feedback control," International Journal of Control, vol. 76, no. 9-10, pp. 924-941, 2003.

[29] M. Djemai, K. Busawon, K. Benmansour, and A. Marouf, "High-order sliding mode control of a DC motor drive via a switched controlled multi-cellular converter," International Journal of Systems Science, vol. 42, no. 11, pp. 1869-1882, 2011.

[30] M. Lavanya, R. M. Brisilla, and V. Sankaranarayanan, "Higher order sliding mode control of permanent magnet dc motor," in Proceedings of the 12th International Workshop on Variable Structure Systems (VSS '12), pp. 226-230, January 2012.

[31] S. Laghrouche, M. Smaoui, F. Plestan, and X. Brun, "Higher order sliding mode control based on optimal approach of an electropneumatic actuator," International Journal of Control, vol. 79, no. 2, pp. 119-131, 2006.

[32] A. G. Loukianov, E. Sanchez, and C. Lizalde, "Force tracking neural block control for an electro-hydraulic actuator via second-order sliding mode," International Journal of Robust and Nonlinear Control, vol. 18, no. 3, pp. 319-332, 2008.

[33] J. Komsta, N. van Oijen, and P. Antoszkiewicz, "Integral sliding mode compensator for load pressure control of die-cushion cylinder drive," Control Engineering Practice, vol. 21, no. 5, pp. 708-718, 2013.

[34] M. Feki, Synthèse de commandes et dobservateurs pour les systèmes non-linèaires: application aux systèmes hydrauliques [Ph.D. thesis], Universitè de Metz, Metz, France, 2001.

[35] V. V. Filippov, "On a scalar equation with discontinuous righthand side and the uniqueness theorem," Differential Equations, vol. 38, no. 10, pp. 1435-1445, 2002.

[36] T. Boukhobza, M. Djemai, and J. P. Barbot, "Nonlinear sliding observer for systems in output and output derivative injection form," in Proceedings of the IFAC World Congress, pp. 299-305, San Antonio, Tex, USA, 1996.

[37] H. Saadaoui, N. Manamanni, M. Djemaï, J. P. Barbot, and T. Floquet, "Exact differentiation and sliding mode observers for switched Lagrangian systems," Nonlinear Analysis, Theory, Methods \& Applications, vol. 65, no. 5, pp. 1050-1069, 2006. 


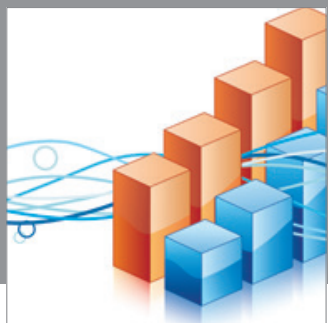

Advances in

Operations Research

mansans

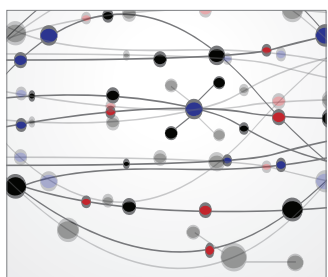

The Scientific World Journal
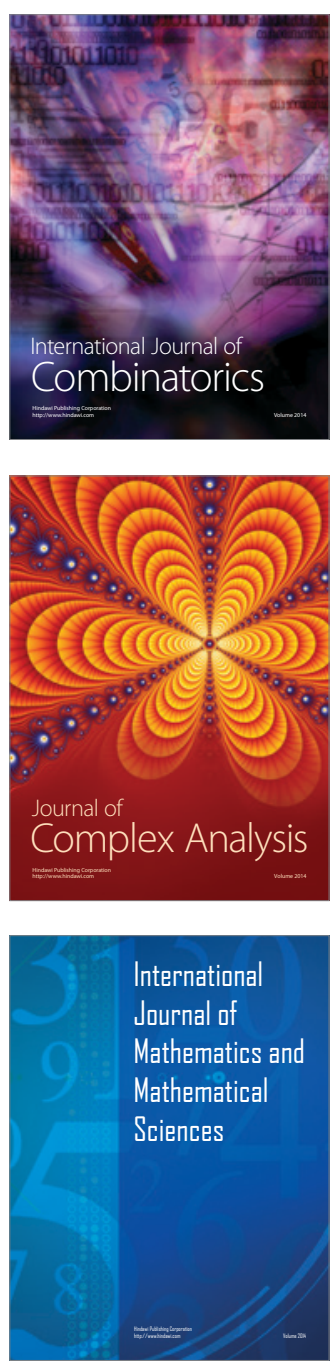
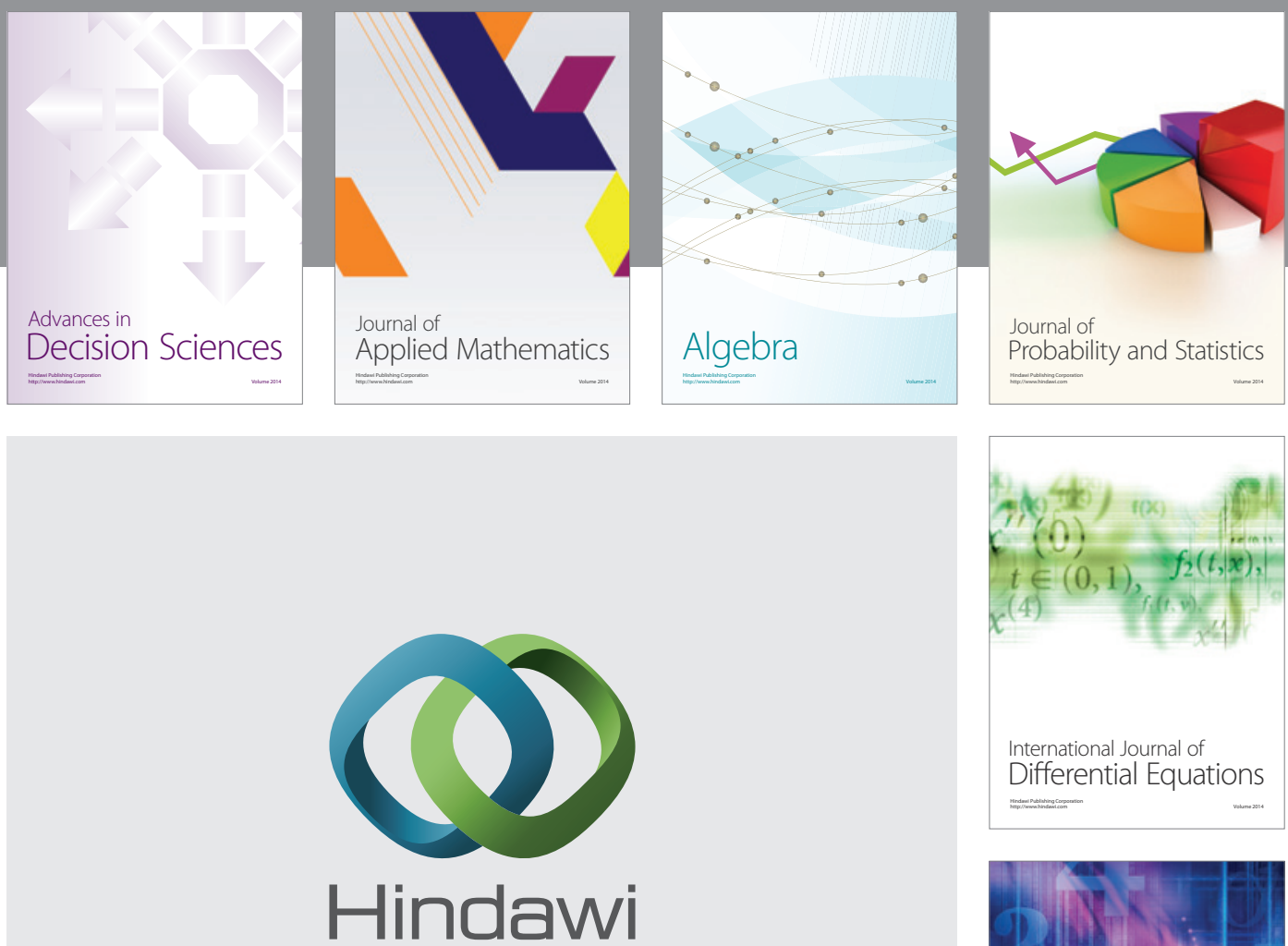

Submit your manuscripts at http://www.hindawi.com
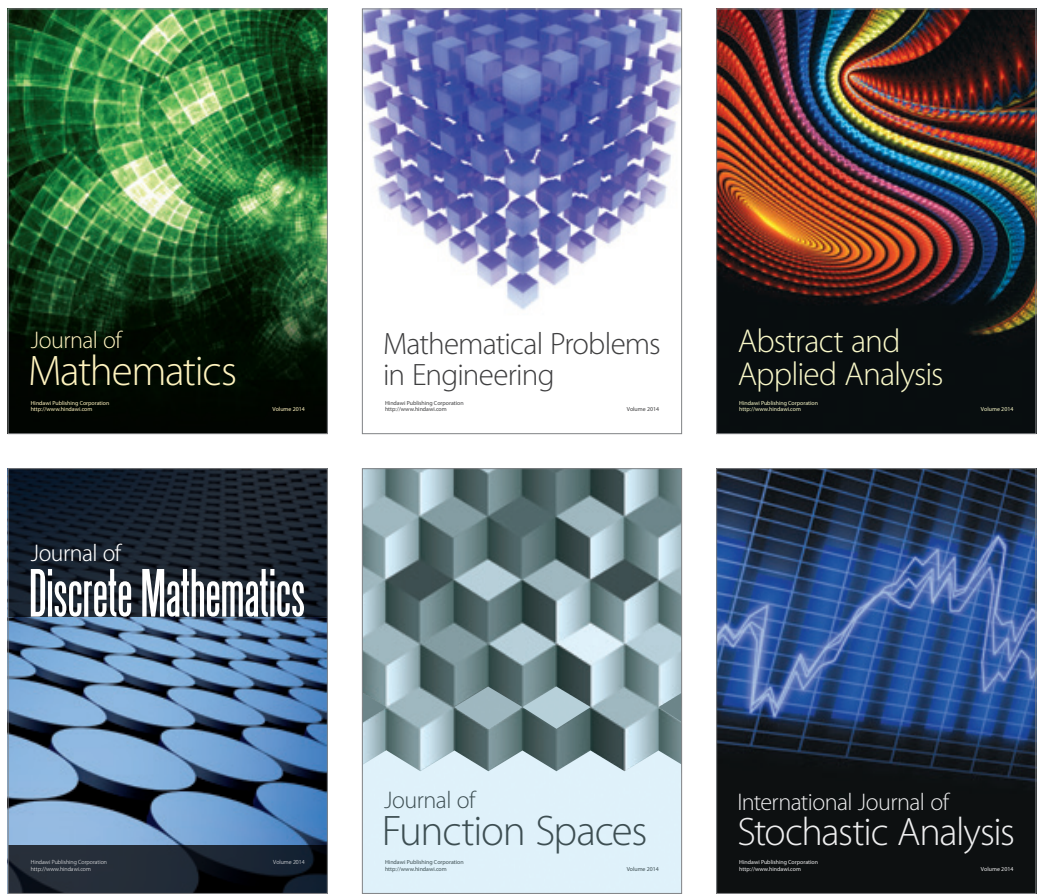

Journal of

Function Spaces

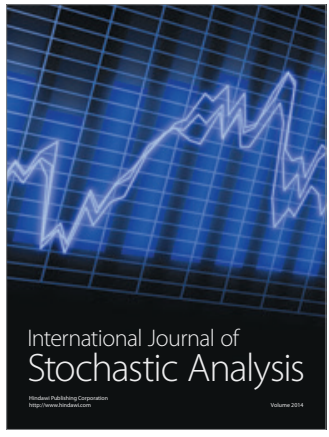

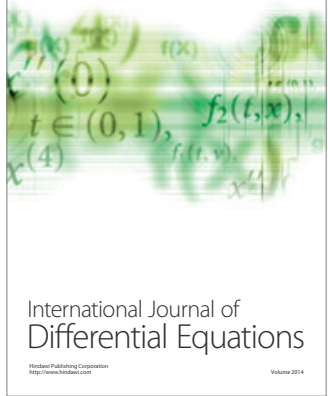
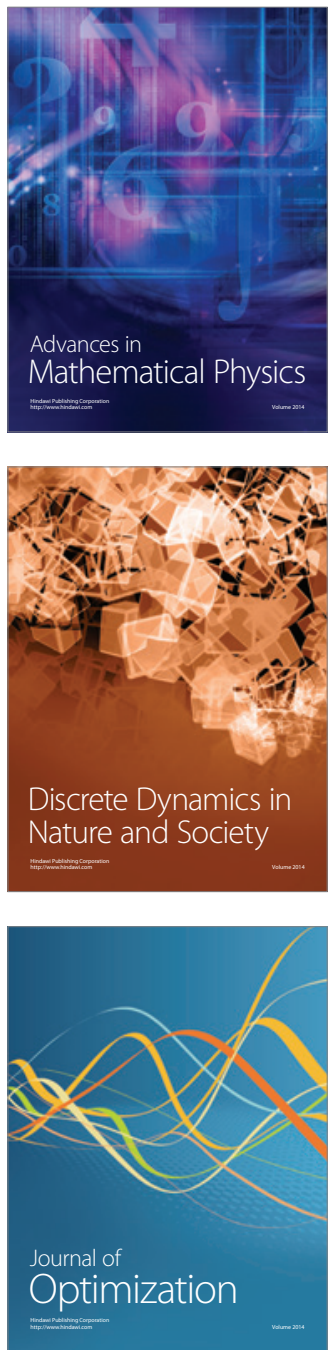